\title{
Phase Behaviour, Fluid Properties and Recovery Efficiency of Immiscible and Miscible Condensate Displacements by $\mathrm{SCCO}_{2}$ Injection: Experimental Investigation
}

\author{
Abdullah Al-Abri and Robert Amin
}

\begin{abstract}
This paper presents a quantitative investigation of the interfacial tension dependent relative permeability (IFT-DRP) and displacement efficiency of supercritical $\mathrm{CO}_{2}$ injection into gas-condensate reservoirs. A high pressure high temperature experimental laboratory was established to simulate reservoir conditions and to perform relative permeability measurements on sandstone cores at a constant reservoir temperature of $95{ }^{\circ} \mathrm{C}$ and displacement velocity of $10 \mathrm{~cm} / \mathrm{hr}$. This investigation covers immiscible displacements (1100 and 2100 psi), near-miscible displacement (3000 psi) and miscible displacements (4500 and 5900 psi).
\end{abstract}

The coreflooding results demonstrated that displacement pressure is a key factor governing the attainment of optimum sweep efficiency. The ultimate condensate recovery increased by almost threefold when $\mathrm{CO}_{2}$ was injected at near-miscible conditions (i.e. 23.40\% ultimate recovery at 1100 psi compared to $69.70 \%$ at $3000 \mathrm{psi}$ ). Miscible flooding was found to give the optimum condensate recovery ( $9 \%$ extra ultimate recovery compared to near-miscible injection). Besides improving the ultimate recovery, miscible floods provided better mobility ratios and delayed gas breakthrough (0.62 PV BT at 5900 psi compared to 0.21 PV BT at 1100 psi). In addition to the elimination of IFT forces in miscible displacements, favourable ratios of fluid properties and phase behaviour relationships between the $\mathrm{SCCO}_{2}$ and condensate were believed to be the driving force for the improved recovery as they provided a stabilising effect on the displacement front and stimulated swelling of the condensate volume.

This paper incorporates the theoretical aspects of phase behaviour and fluid properties that largely affect the microscopic displacement efficiency and serves as a practical guideline for operators to aid their project designs and enhance their recovery capabilities.

\section{Introduction}

Improved Hydrocarbon Recovery (IHR) refers to recovery over and above that obtained through the natural energy of the reservoir. IHR practices are usually considered when the first (natural) energy of the reservoir crises. The efficiency of IHR techniques depends on both the microscopic as well as the macroscopic sweep-out. The design of such methodologies requires careful engineering consideration of reservoir heterogeneities, gravity override, viscous fingering and the existence of fractures. These factors form the crux of the reservoir engineering difficulties associated with IHR in conventional gas/oil accumulations, but offers even greater challenges in gas condensate reservoirs owing to the complex fluid dynamics of the two coexisting phases. Gas-condensate reservoirs are increasingly becoming more common as developments are encountering greater depths, and thus greater pressures and temperatures.

Carbon dioxide $\left(\mathrm{CO}_{2}\right)$ injection for IHR continues to gain momentum and shows promise for further gains in the foreseeable future despite recent swings in oil prices. $\mathrm{CO}_{2}$ injection into hydrocarbon reservoirs offers many advantages over other dry hydrocarbon gases, flue gases and nitrogen. Research shows that the minimum miscibility pressure (MMP) of $\mathrm{CO}_{2}$ is substantially lower than the miscibility pressure for the counterpart gases (Green and Willhite, 1984). The Supercritical $\mathrm{CO}_{2}\left(\mathrm{SCCO}_{2}\right)$ density, in addition, is much closer to typical light oil densities than are most other gases, making $\mathrm{CO}_{2}$ less prone to gravity segregation. The higher viscosity of $\mathrm{CO}_{2}$ compared to other gases makes injectivity problems less severe.

There are three classes of $\mathrm{CO}_{2}$ flooding processes: miscible, near-miscible and immiscible (Stalkup, 1992; Blunt et al., 1993). The immiscible $\mathrm{CO}_{2}$ process is a non-thermal recovery method that has considerable promise for a range of heavy reservoirs. In this method, a slug of $\mathrm{CO}_{2}$ gas is injected into the formation, which mobilizes the oil contacted and displaces it towards the production well. Oil mobility is improved due to the solubility of $\mathrm{CO}_{2}$ in the oil that causes a reduction in the viscosity, and an increase in the net volume. The recovery process must be supplemented by a suitable mobility control method as the $\mathrm{CO}_{2}$ alone cannot displace the oil efficiently (Rojas, 1985; Rojas and Farouq, 1986; Dyer, 1989). In 
miscible $\mathrm{CO}_{2}$ flooding operations, liquid (more correctly, above the critical point) $\mathrm{CO}_{2}$ is injected into the reservoir to form a single-phase solution with the in-place oil which is thus displaced as a highly mobile phase. Moreover, the retentive force of capillarity, which is a significant factor in reducing the recovery efficiency in conventional flood operations, is eliminated or minimized due to a reduction in interfacial tension. Oil swelling, mass transfer, oil viscosity reduction, vaporization and extraction of intermediate components from the oil all play a role in this transition bank between the two fluids. This method provides an effective displacement of the oil in the areas swept by the liquefied $\mathrm{CO}_{2}$, so that a low residual oil saturation is obtained. The efficiency of the process depends on reservoir temperature and pressure, which influence the crude oil- $\mathrm{CO}_{2}$ miscibility (Monger et al., 1991; Thomas and Monger, 1991; Monger and Coma, 1988).

Although numerous studies of $\mathrm{CO}_{2}$ injection into conventional crude oil reservoirs have been developed and implemented in practice, very little work has been established on enhanced gas and condensate recovery by $\mathrm{CO}_{2}$ injection. This experimental investigation has taken this challenge with studies dedicated towards the evaluation of enhanced condensate recovery following immiscible and miscible $\mathrm{SCCO}_{2}$ injection. The displacement effectiveness and recovery efficiency of each scenario under investigation was tied up with the physical properties and phase behaviour of the binary mixture of $\mathrm{CO}_{2}$ and condensate.

\section{Microscopic Displacement Efficiency}

The microscopic performance of a displacement process is governed by viscous and capillary forces. The pore space is normally the battleground of these forces. Mathematically, the microscopic displacement efficiency $\left(E_{D}\right)$ can be expressed as:

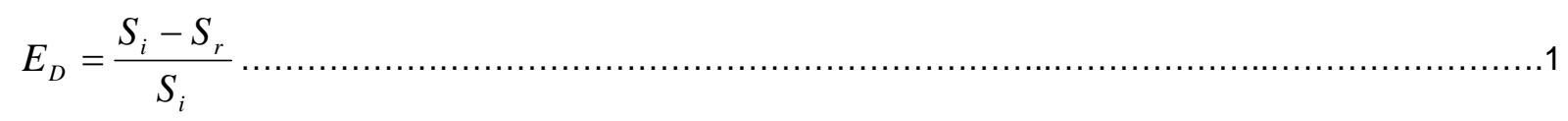

where $S_{i}$ and $S_{r}$ are initial and residual hydrocarbon saturations respectively.

Viscous forces, in fluid mechanics, are defined as the forces per unit volume arising from viscous effects in fluid flow. Viscous forces are a strong function of the rate at which the fluid velocity is changing over distance. Capillary forces tend to retain the oil behind the displacement front. These capillary forces are a result of the interfacial tension (IFT) between the displacing fluid and the oil in place.

The ratio of viscous over capillary forces can be demonstrated by a dimensionless capillary number as:

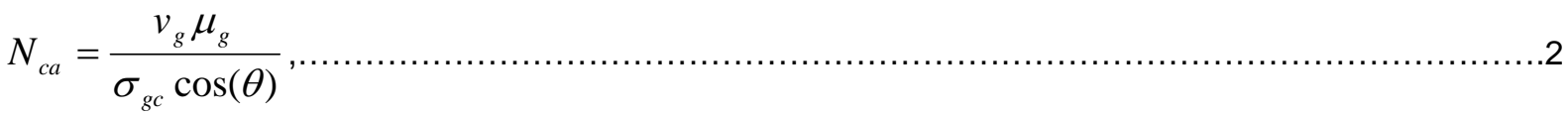

with $v_{g}$ being the gas velocity, $\mu_{g}$ being the gas viscosity, and $\sigma_{g c}$ being the interfacial tension between $\mathrm{SCCO}_{2}$ and condensate.

Moore and Slobod (1956) were among the first researchers to develop a correlation between residual saturation and the capillary number. This correlation illustrates that the higher the capillary number the lower the residual saturation of the displaced phase becomes, resulting in higher recovery of the displaced phase. Figure 1 shows a typical correlation between the capillary number and residual saturation for a water-wet system. Bardon and Langeron (1980) and Stegemeier (1974) suggest that the capillary number for waterflooding displacements ranges from $10^{-8}$ to $10^{-7}$. 


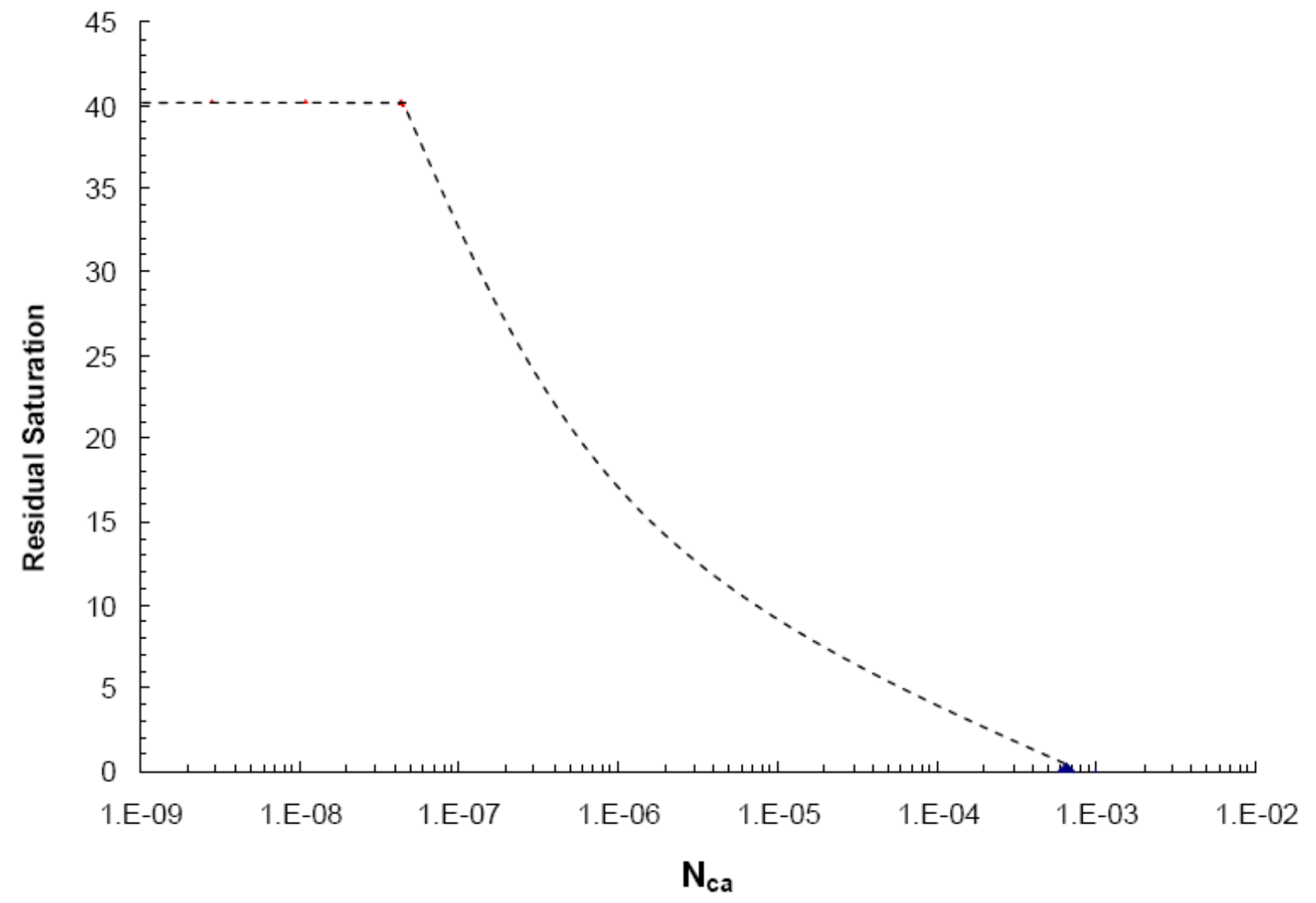

Figure 1: A typical capillary number-residual saturation curve

In order to design an immiscible displacement process that is more efficient than waterflooding, a high capillary number must be attained. For attaining a high capillary number either the interstitial velocity or viscosity has to be increased. Alternatively, the IFT may be decreased. Rogers and Grigg (2000) suggest that the IFT is the most sensitive and the most easily modified parameter, and suggest that considerable decrease in IFT at relatively low cost is the benefit of miscible flooding.

Therefore, if by some means IFT is eliminated, the capillary forces would be removed. Since there is no resisting force confronting viscous forces, this miscible condition is expected to yield a complete oil recovery in areas contacted by the displacing fluid. There will be no discrete interfacial barrier between the fluids in the microscopic displacement of fully miscible fluids. This prevents the interpenetration of their molecules. There seems, however, to be no consensus in the literature for the need for development of miscibility in gas floods (Jakupsstovu et al., 2001; Schramm, 2000; Thomas et al., 1995). Overlapping values of IFT for immiscible, near-miscible and miscible floods have been reported (Bardon and Langeron, 1980; Rao, 2001; Taber et al., 1996).

Shyeh-Yung (1991) was first to point out the 'incentives' of $\mathrm{CO}_{2}$ injection in oil-bearing accumulations at near-miscible conditions. The most important advantages of near-miscible injection are cost efficiency and operational feasibility. This is attributed to the fact that less energy input is required for gas compression at near-miscible conditions and not all reservoirs are candidates for miscible flooding. Shyeh-Yung stated also other potential benefits that make the near-miscible choice even more attractive such as:

- Relatively high oil recovery, close to what is expected from miscible processes. The low IFT would be responsible for high recovery.

- Improved sweep efficiency at lower pressures due to formation of liquid phase. 
Thomas et al. (1994) investigated the effects of IFT and viscosity ratio and evaluated the optimal gas injection schemes associated with near-miscible flooding conditions. They examined the importance of heterogeneity and stated that when the pore size distribution is uniform with relatively small pore throats, IFT plays an important role. These investigations concluded that near-miscible systems perform in a 'comparable manner' to miscible injections.

\section{Phase Behaviour and Fluid Properties}

All IHR mechanisms should, in principle, be designed to handle complex fluid mixtures whose behaviour is strongly dependent on their chemical makeup. The key to mastering an efficient and profitable extraction of components associated with $\mathrm{CO}_{2}-\mathrm{IHR}$ lie in the phase behaviour and fluid properties of the mixtures. One of the most useful phase behaviour visualisations is the pressure-concentration envelope. Aspen Hysys Simulation Package (AspenTech Co., 2009) was used to predict the thermodynamic state of the $\mathrm{CO}_{2}$-condensate mixture at various injection pressures. The composition of this condensate sample is discussed in Section 4.2. Figure 2 depicts that the original condensate $\left(0 \% \mathrm{CO}_{2}\right)$ is a liquid at pressures above approximately 3100 psi but splits into liquid and vapour below that pressure. A mixture containing $15 \mathrm{~mole} \% \mathrm{CO}_{2}$ forms a single liquid phase above $3400 \mathrm{psi}$ and a liquid and a vapour $\left(\mathrm{CO}_{2}\right.$ and light hydrocarbons) at lower pressures. Two liquids form at high pressures and $\mathrm{CO}_{2}$ concentrations, a dense $\mathrm{SCCO}_{2}$-rich phase and an oil-rich liquid.

Figure 2 also indicates that $\mathrm{CO}_{2}$ is fairly soluble in condensates at typical reservoir pressures, but it is not miscible in all proportions at any reasonable pressure. The $\mathrm{CO}_{2}$ mole fraction must, for instance, be nearly 0.55 before a second dense $\mathrm{SCCO}_{2}$-rich phase appears at 5000 psi. Thus, when $\mathrm{CO}_{2}$ is injected into the reservoir and contacts trapped condensate, at first it simply dissolves in the condensate droplets. This favourable phase behaviour relationship results in the swelling of condensate volume leading to improved recovery.

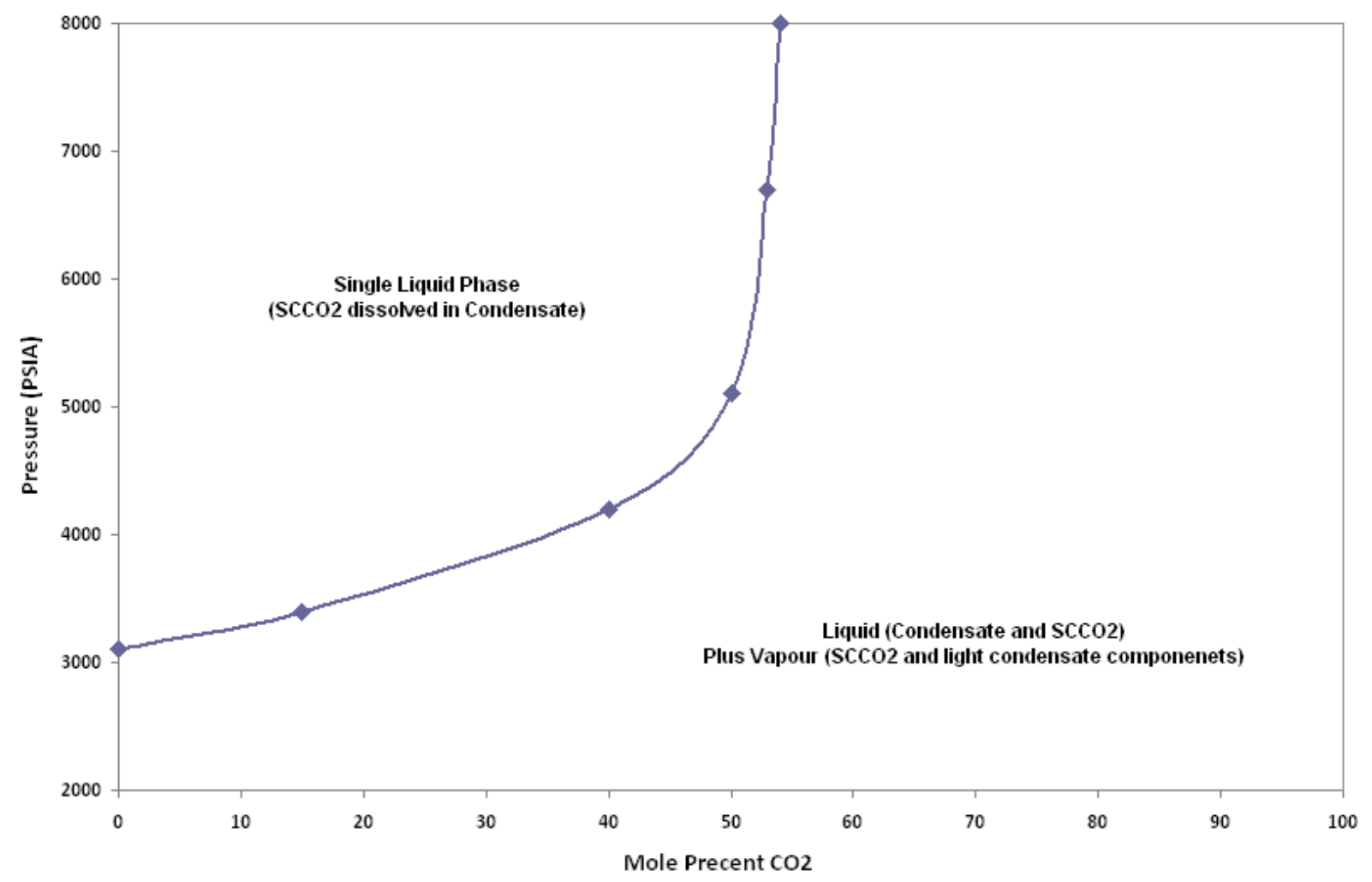

Figure 2: Phase behaviour of binary mixtures of $\mathrm{CO}_{2}$ and condensate at $95{ }^{\circ} \mathrm{C}^{15}$

PVT simulations, utilizing PVTSim Package from Calsep Company, was used to calculate the $\mathrm{CO}_{2}$ and condensate physical properties at various pressures. The simulator used SRK Peneloux equation of state 
(EOS) to calculate the viscosity and density of each fluid at $95{ }^{\circ} \mathrm{C}$. Figure 3 below demonstrates the condensate $/ \mathrm{CO}_{2}$ density ratio (blue line) and viscosity ratio (red line) for the choice of pressures. The gravitational force tends to pull liquid condensate downwards towards the lower edge of the pore channel. This force was always present as displacement experiments were done horizontally. Gravity segregation would be expected to be more pronounced at lower injection pressures as the condensate remains the denser phase. This means that the $\mathrm{CO}_{2}$ would mostly sweep-out the top part of the core sample leading to poor sweep efficiency. Viscosity ratio is another important design parameter that influences the stability of the flood front. The reduction in the condensate over $\mathrm{CO}_{2}$ viscosity ratio with higher pressures would be expected to yield a stabilising effect on the front.

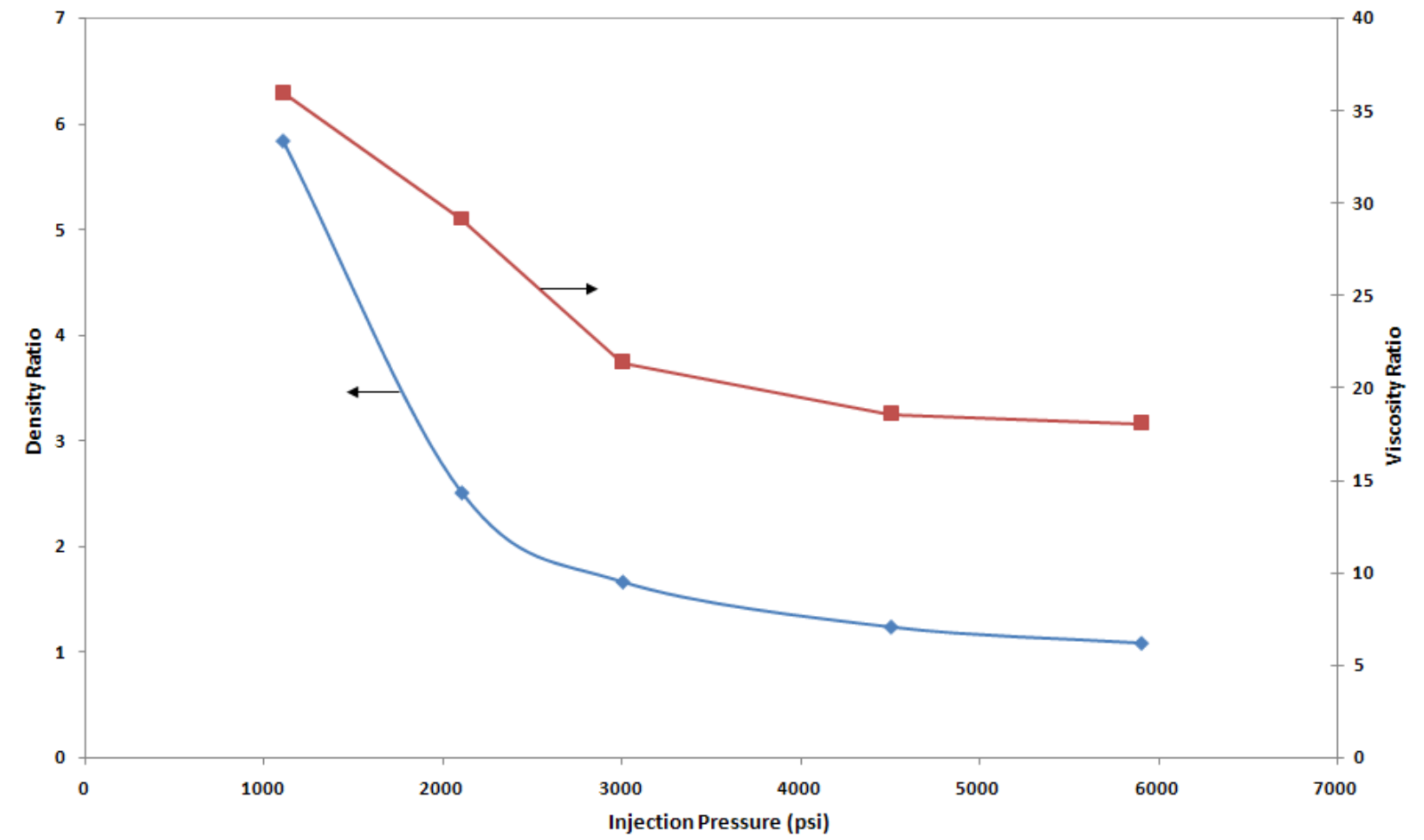

Figure 3: Condensate- $\mathrm{SCCO}_{2}$ density and viscosity ratios for all injection pressure scenarios ${ }^{16}$

\section{Experimental Apparatus and Procedures}

\subsection{Experimental Core Properties}

All experiments were carried out on a reservoir sandstone core plug from a gas condensate field in the North Western Shelf of Australia. The water-wet core has the following petrophysical characteristics: 6.9 $\mathrm{cm}$ length, $3.8 \mathrm{~cm}$ diameter, $13.2 \%$ porosity, and 22 md effective permeability. The connate water saturation is believed to have remained constant during the course of the tests, as the core effective permeability remained unchanged and no water production was observed.

\subsection{Experimental Test Fluids}

The standard stock tank condensate sample utilized during coreflooding was supplied by Core Laboratory Australia. The composition of this sample is provided in Table 1 (Appendix 1). It has a calculated density of $0.8161 \mathrm{~g} / \mathrm{cc}$ at $23{ }^{\circ} \mathrm{C}$ and a molecular weight of $175.8 \mathrm{~g} / \mathrm{mol}$. Table 1 shows that no methane or ethane components are present and that $\mathrm{C} 1-\mathrm{C} 10$ forms 38.93 mole\% of the sample. Industrial $\mathrm{CO}_{2}$ gas was supplied to our laboratory by BOC Gases Australia. The brine was synthetically made based on water analysis from the reservoir. The PVT properties of the fluids were calculated using the Peng-Robinson EOS.

\subsection{Experimental Design}

The experimental design adopts the unsteady state procedure in which effluent production from the core sample was recorded during the course of the imposed displacement processes. A high pressure high 
temperature experimental laboratory was commissioned to observe fluid displacements in core samples while simulating subsurface reservoir conditions including temperature, pore pressure, and overburden pressure. The schematic drawing of the facility is shown in Figure 4. It consists of a high-pressure pump (LC-20AT Shimadzu), titanium accumulators with floating pistons, check valves and a back-pressure regulator (BPR), a core holder, a gas meter and a gas analyser, and an online data collection instrument synchronized to a laboratory PC. The pressure of the flooding fluids inside the titanium vessels was maintained by injecting or withdrawing water from the bottom of the cells. High-pressure steel piping (1/8" ID) carried the fluids to the appropriate injection ports in the core holder. The produced fluids were carried through the BPR first and then into a graduated measuring cylinder. The core holder, backpressure regulators, fluid accumulators and flow lines were accommodated inside a temperature-controlled, airforced circulation oven. The simulated reservoir temperature was maintained with a thermocouple that possesses an accuracy deviation of $0.5{ }^{\circ} \mathrm{C}$. Pressure transducers located at the inlet and outlet of the core were used to measure the pressure drop across the core. The transducers provided stable differential pressure data with an accuracy of 0.01psi during the course of the tests. The composition of the produced gas was monitored on the spot and on a continuous bases by a $\mathrm{CO}_{2}$ gas analyser (PEM tech gas analyser) and recorded on the integrator. The volume of produced gas was also measured by a flow meter. This experimental design is robust and special in the sense that it handles high pressure and high temperature conditions as well as it controls the whole flooding process digitally, thus minimises experimental errors.

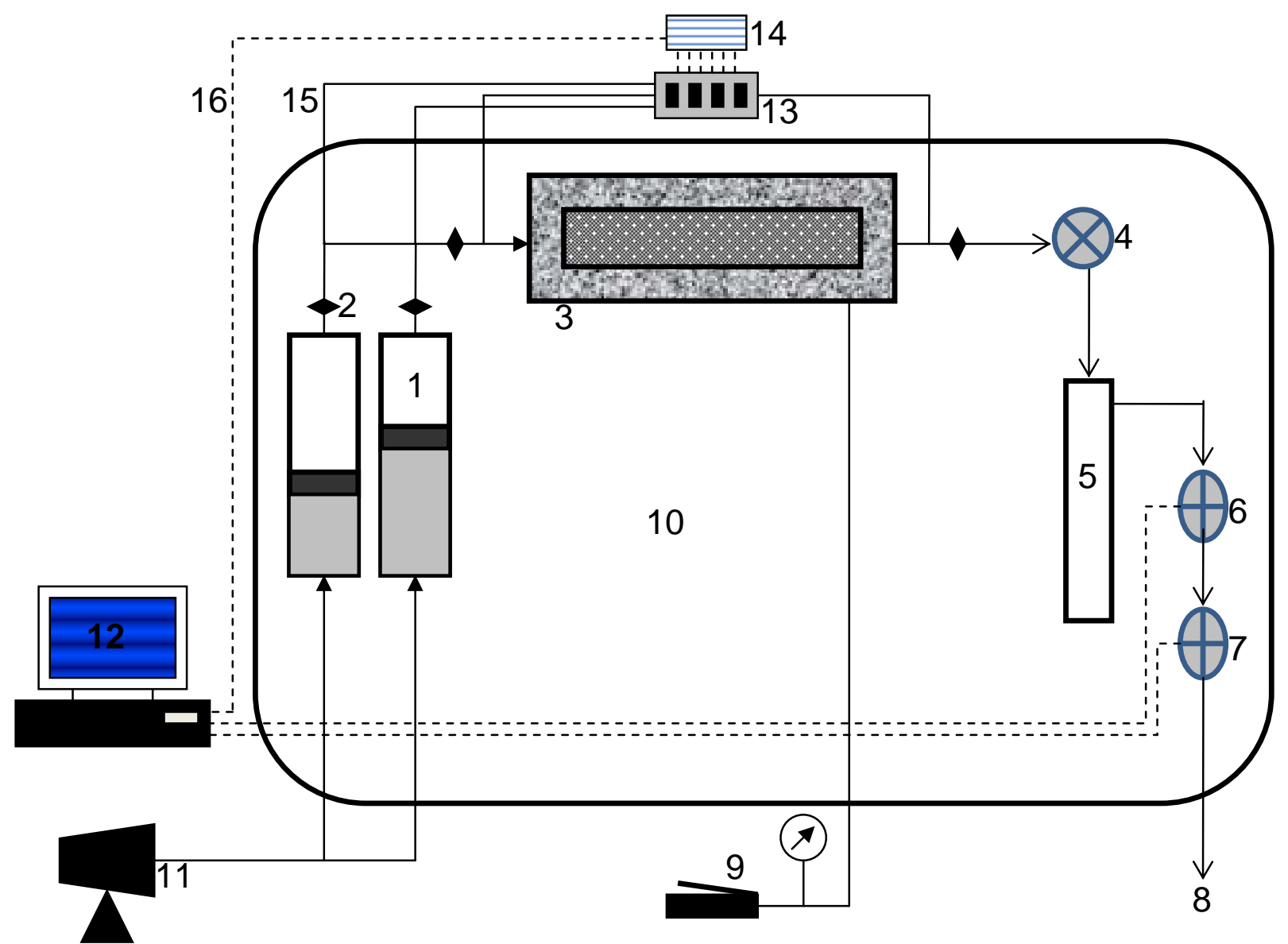

Figure 4: HPHT coreflooding rig schematic

Legend for the above schematic:

1: HPHT fluid accumulators with floating pistons, 2: one-way valve, 3: core holder, 4: back pressure regulator, 5: separator, 6: gas flow meter, 7: gas analyser, 8: vent, 9: hand pump to control annulus 
pressure, 10: temperature-controlled oven, 11: Shimadzu pump, 12: laboratory computer, 13: pressure transducers, 14: data-taker ${ }^{\mathrm{TM}}, 15: 1 / 8$ " high pressure piping, and 16: instrumentation lines.

\subsection{Experimental Procedures}

Initial porosity and single phase permeability measurements were done prior to the establishment of connate water saturation. Conventional unsteady-state relative permeability curves were generated by initially saturating the core with condensate and then injecting $\mathrm{SCCO}_{2}$ gas at predetermined flooding pressure. When the two phase flow occurred after gas breakthrough, the data required to calculate relative permeability were carefully measured. The JBN and the Jones-Roszelle procedures were used to construct the relative permeability curves versus saturation. The $\mathrm{SCCO}_{2}$ injection continued until 10 pore volumes of injection $(\mathrm{PVI})$.

\section{Results and Discussion}

The experimental work incorporated the online monitoring of condensate production and $\mathrm{CO}_{2}$ breakthrough versus the pore volumes of gas injection (PVI). All measurements were carried out at a simulated reservoir temperature of $95{ }^{\circ} \mathrm{C}$ and pore pressures of $1100,2100,3000,4500$ and 5900 psi; corresponding to earlier IFT measurements reported by authors as $12.56,6.28,1.11,0,0$ dyne/cm respectively (Al-Abri and Amin, 2009a). The MMP was measured to be at 3120 psi. The $\mathrm{CO}_{2}$ displacement velocity was maintained constant as $10 \mathrm{~cm} / \mathrm{hr}$ throughout all investigation scenarios. Although this velocity was chosen to be of particular relevance to real oil displacements by gas injection, its value is believed to be well above ( 3 orders of magnitude) the maximum flow velocity required for a completely stable gas injection process in oil-bearing formations. This low flow rate is required to overcome the tendency for $\mathrm{SCCO}_{2}$ fingers to protrude into the condensate. Flow rates above this value would be expected to initiate unstable viscous fingers (Al-Abri and Amin, 2009b).

The following figures (Figure 5-9) demonstrate the experimental results. These results are based on experimental observations of the condensate recovery profile and $\mathrm{CO}_{2}$ breakthrough at the effluent as a function of PVI which differ from the bulk of previous studies owing to great ability of $\mathrm{CO}_{2}$ to swell, vaporise and mobilise the condensate (high medium components) as opposed to conventional crude oils. Of remarkable note is Figure 8 which shows how the condensate residual saturation changes with IFT the main target of this research line.

Figure 5 below shows the percent condensate recovery factor as a function of $\mathrm{PVI}$ for the different displacement pressures. The dashed arrows indicate the condensate recovery percent at breakthrough. In the 5900 psi miscible flood, breakthrough of $\mathrm{SCCO}_{2}$ gas occurred at $0.62 \mathrm{PVI}$. Condensate production continued after breakthrough recovering 73.33 and $77.20 \%$ of the original oil in place (OOIP) at 1.2 and 2.2 PVI respectively. The condensate production was very slow after 1.5 PVI. The ultimate production was $78.9 \%$ OOIP at $6 \mathrm{PVI}$. In the 3000 psi near-miscible flood, breakthrough of gas occurred at $0.54 \mathrm{PVI}$. Condensate production increased to 64.16 and $68.74 \%$ of OOIP at 1 and 2 PVI respectively. The final production was $69.72 \%$ OOIP at $6 \mathrm{PVI}$. In the 1100 psi immiscible flood, breakthrough of $\mathrm{SCCO}_{2}$ gas occurred at $0.21 \mathrm{PVI}$. Condensate production continued after breakthrough recovering 22.91 and $23.83 \%$ of the original oil in place (OOIP) at 0.8 and $4 \mathrm{PVI}$ respectively. The ultimate condensate recovery in all cases did not increase appreciably after breakthrough. Condensate recoveries at $0.10 \mathrm{PVI}$, for example, were 13.74, 13.31, 12.57, 9.92 and 9.65\% OOIP for 1100, 2100, 3000, 4500 and 5900 psi injection pressures respectively. Lower displacement pressures yield relatively better condensate recovery at the start of the flooding programme $(4.09 \%$ OOIP total difference at $0.10 \mathrm{PVI})$. This is not surprising as $\mathrm{CO}_{2}$ solubility is expected to be less at lower pressures. Although injection at high (i.e. miscible) pressures may seem to result in less recovery per PVI at the beginning, it actually gives optimum and breakthrough recoveries. 


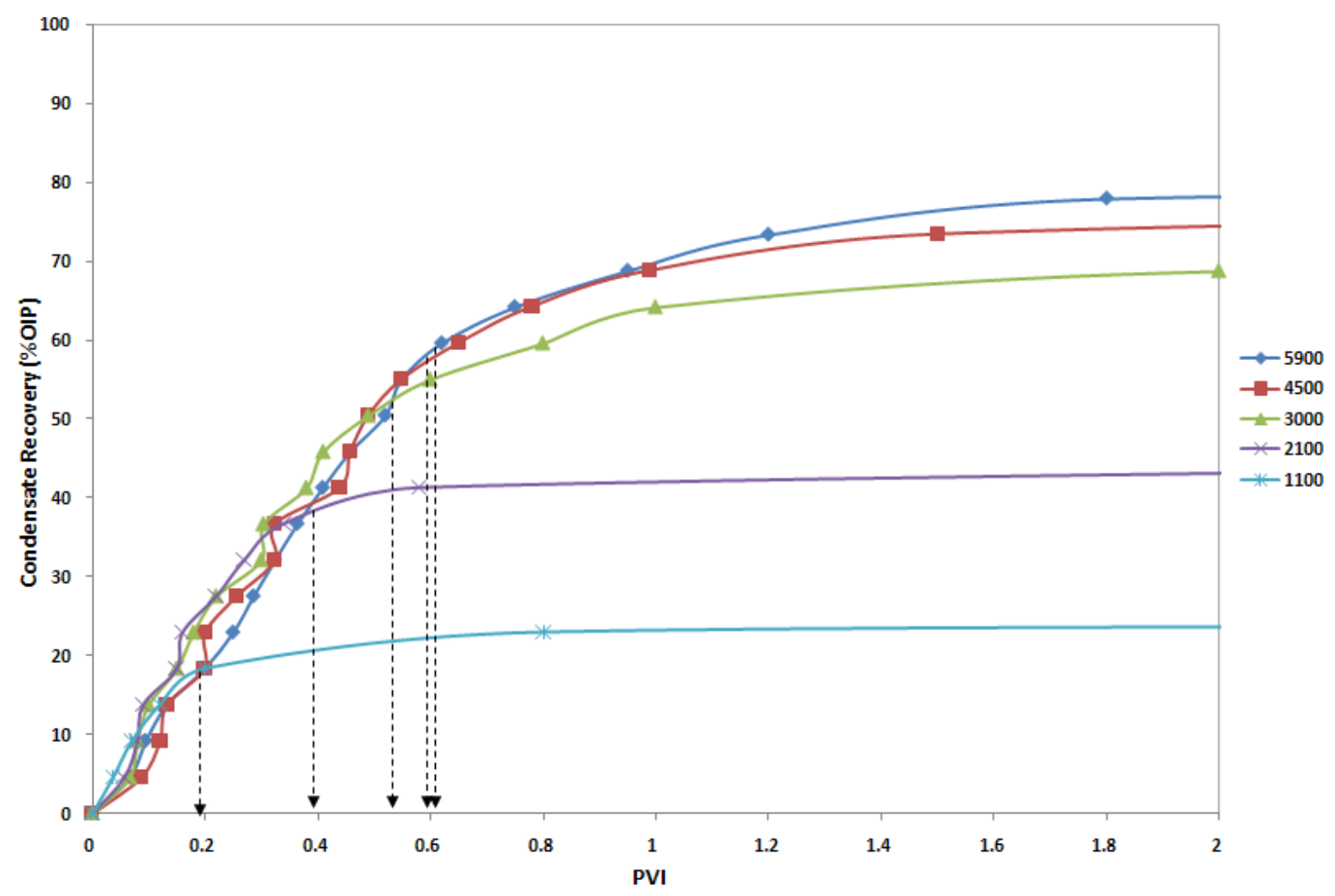

Figure 5: Pressure-dependent condensate recovery profiles

The $\mathrm{SCCO}_{2}$ mole precent produced after breakthrough is demonstrated graphically as a function of PVI in Figure $6 . \mathrm{SCCO}_{2}$ breakthrough was observed to occur at $0.62,0.60,0.54,0.41,0.21 \mathrm{PVI}$ corresponding to condensate recoveries of 59.70, 59.41, 53.12, 38.51 and $18.33 \%$ OOIP for 5900, 4500, 3000, 2100 and 1100 psi injection pressures respectively. Higher injection pressures were seen to result in a delayed gas breakthrough (0.41 PVI total difference). 


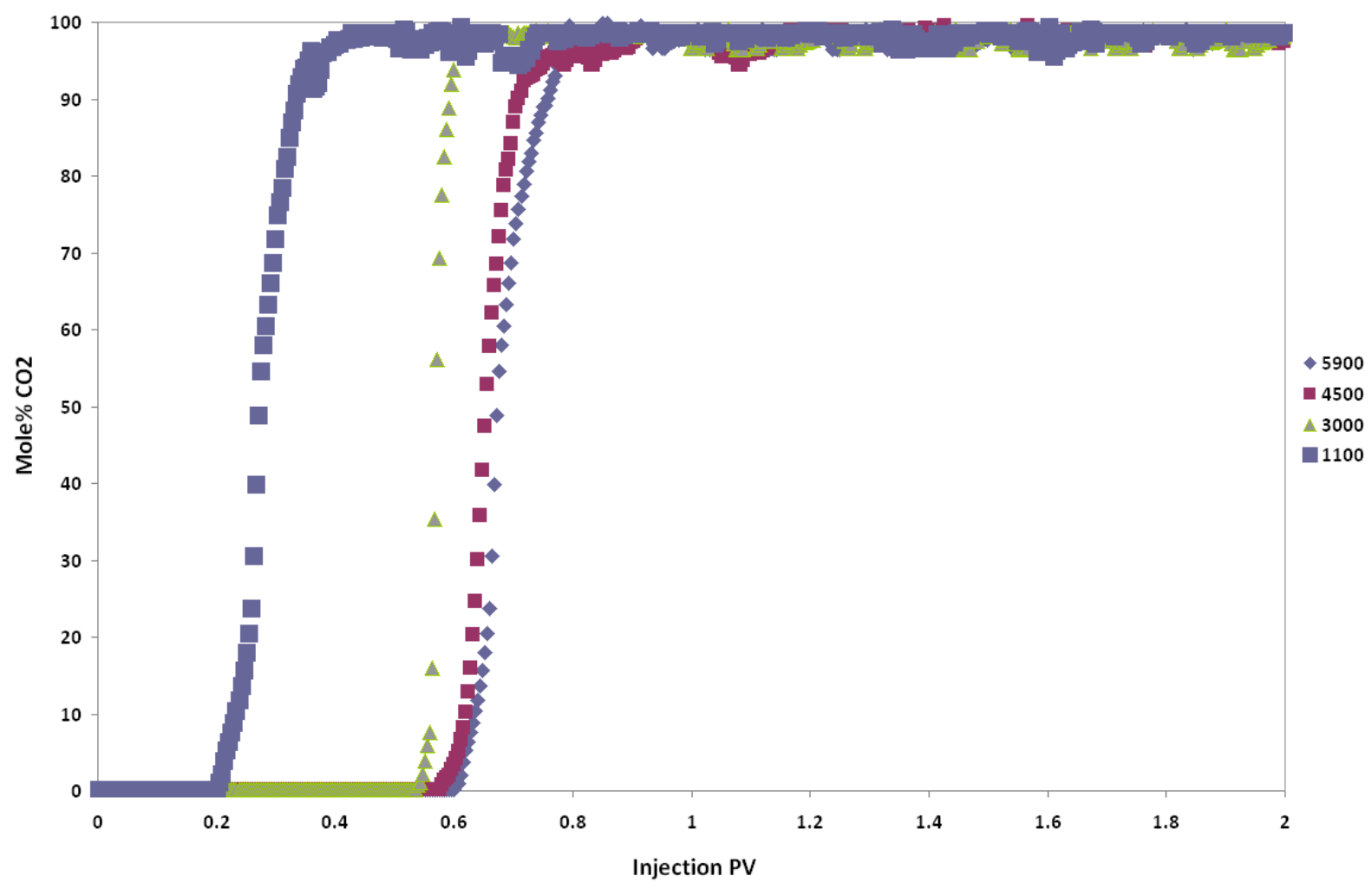

Figure 6: Mole precent $\mathrm{SCCO}_{2}$ production vs. PVI

Figure 7 presents the ultimate and breakthrough condensate recovery factor for various $\mathrm{SCCO}_{2}$ injection pressures at constant flooding velocity and temperature of $10 \mathrm{~cm} / \mathrm{hr}$ and $95{ }^{\circ} \mathrm{C}$, respectively. The graph indicates that high injection pressures lead to high ultimate recovery of condensate. The sweep efficiency, which is a measure of the effectiveness of any EOR process, decreases from 78.9 to $23.4 \%$ OOIP when pressure decreases from 5900 to 1100 psi, respectively. 


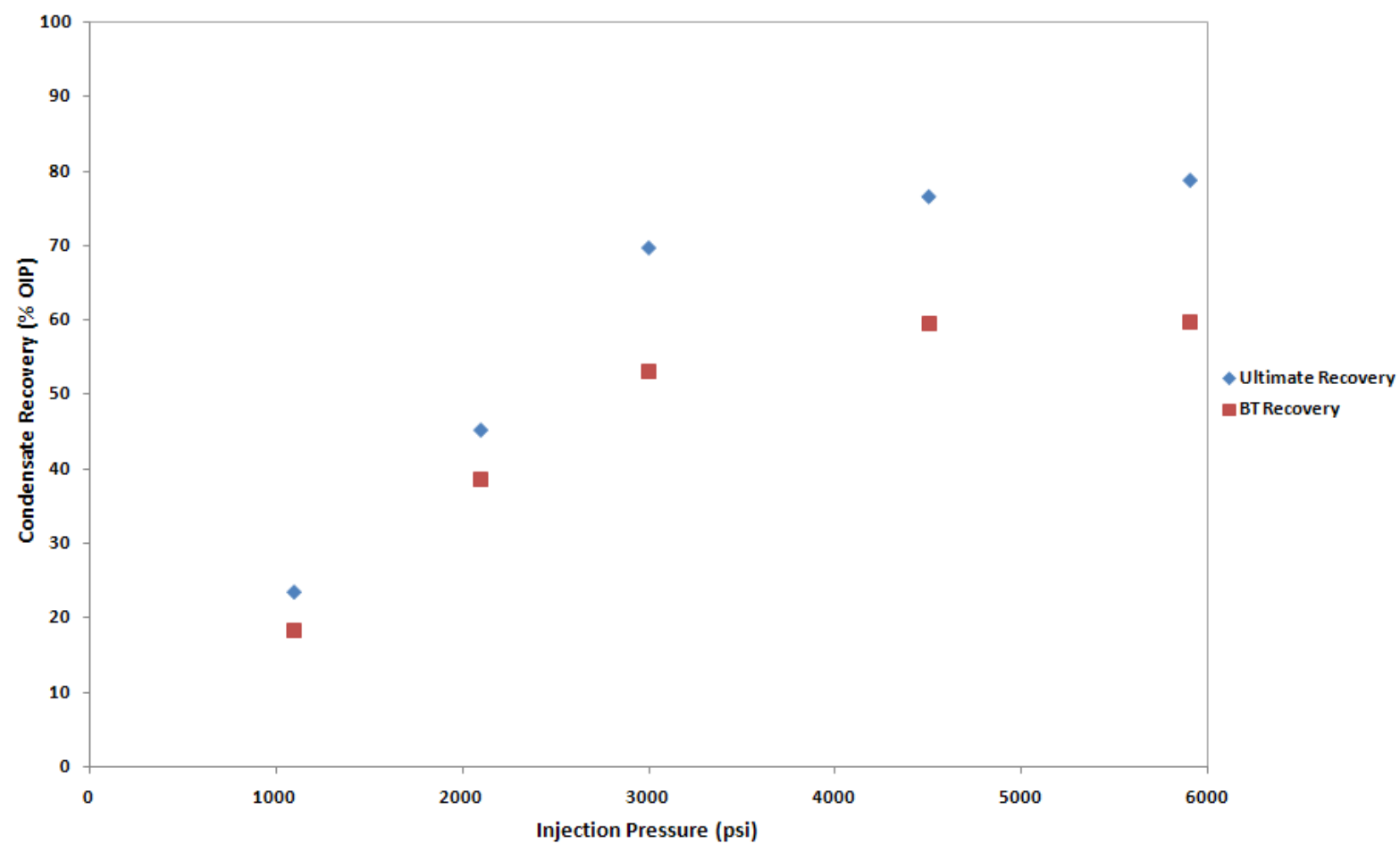

Figure 7: Pressure-dependent ultimate and breakthrough condensate recoveries

While increasing the injection pressure increases the $\mathrm{CO}_{2}$ gas viscosity more than three-folds, increasing the injection pressure reduces significantly the interfacial tension (IFT) and thus increases the capillary number. Figure 8 shows the residual oil saturation as a function of IFT. It outlines that more residual oil saturation $\left(\mathrm{S}_{\mathrm{or}}\right)$ existed at lower flooding pressures possibly due to capillary instabilities that come into play at the flood front, but mostly due to the efficiency of the displacement process. 


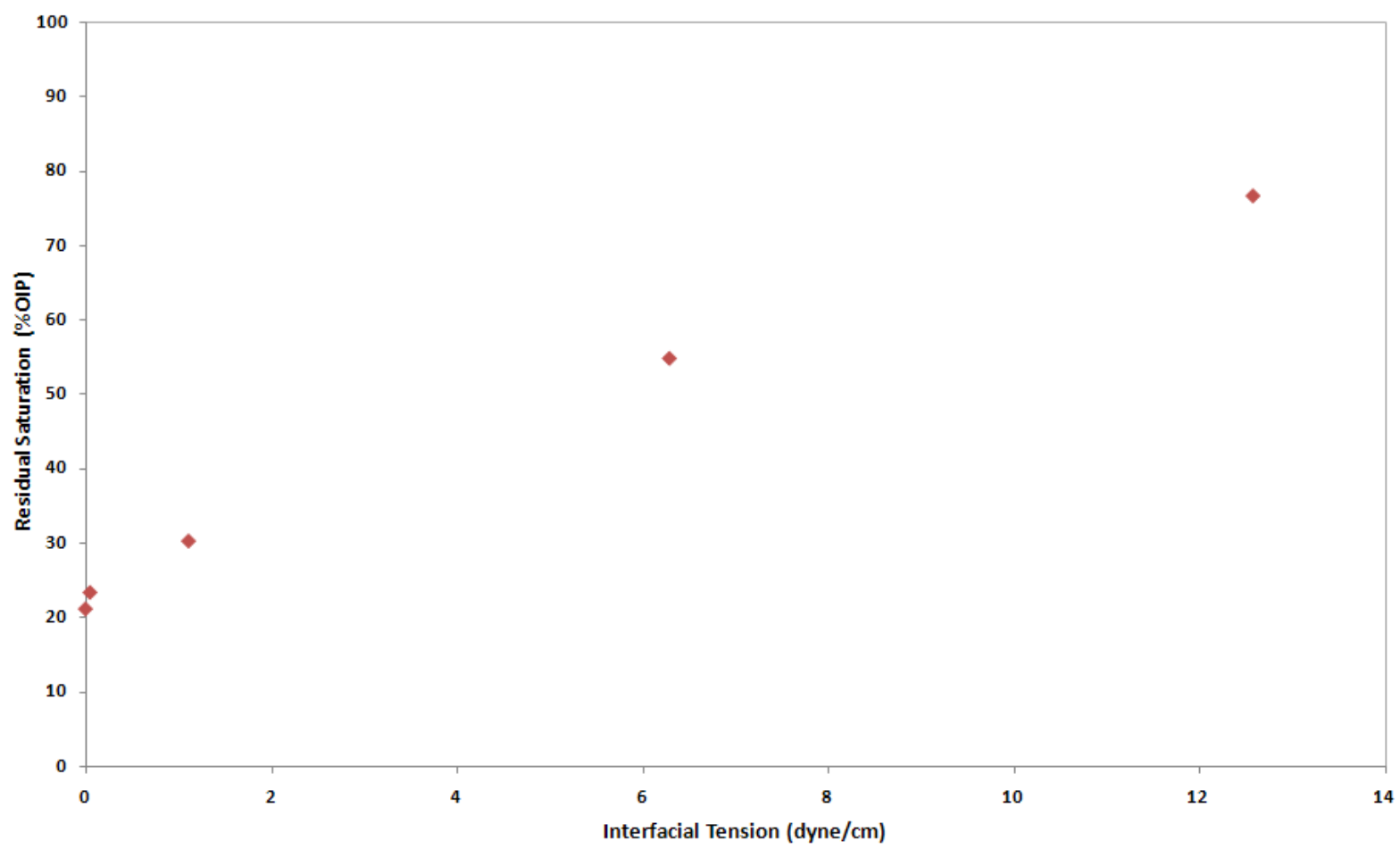

Figure 8: IFT dependent residual saturation for all injection pressure scenarios

The pressure-dependent relative permeability curves associated with $\mathrm{SCCO}_{2}$ injection are shown graphically as a function of the total fluid saturation inside the core in Figure 9 . The irreducible water saturation $\left(\mathrm{S}_{\text {wi }}\right)$ for core sample was $23.3 \%$ PV. The graph illustrates that critical gas saturations and residual condensate saturations are pressure-dependent. Critical gas saturations varied from around 0.065 to 0.11 , and residual condensate saturations changed from 76.6 to $21.2 \%$ PV for injection pressures of 1100 and 5900 psi, respectively. As the displacement pressure increases the capillary numbers improves resulting in lower residual saturation of the condensate and thus higher recovery efficiency. 


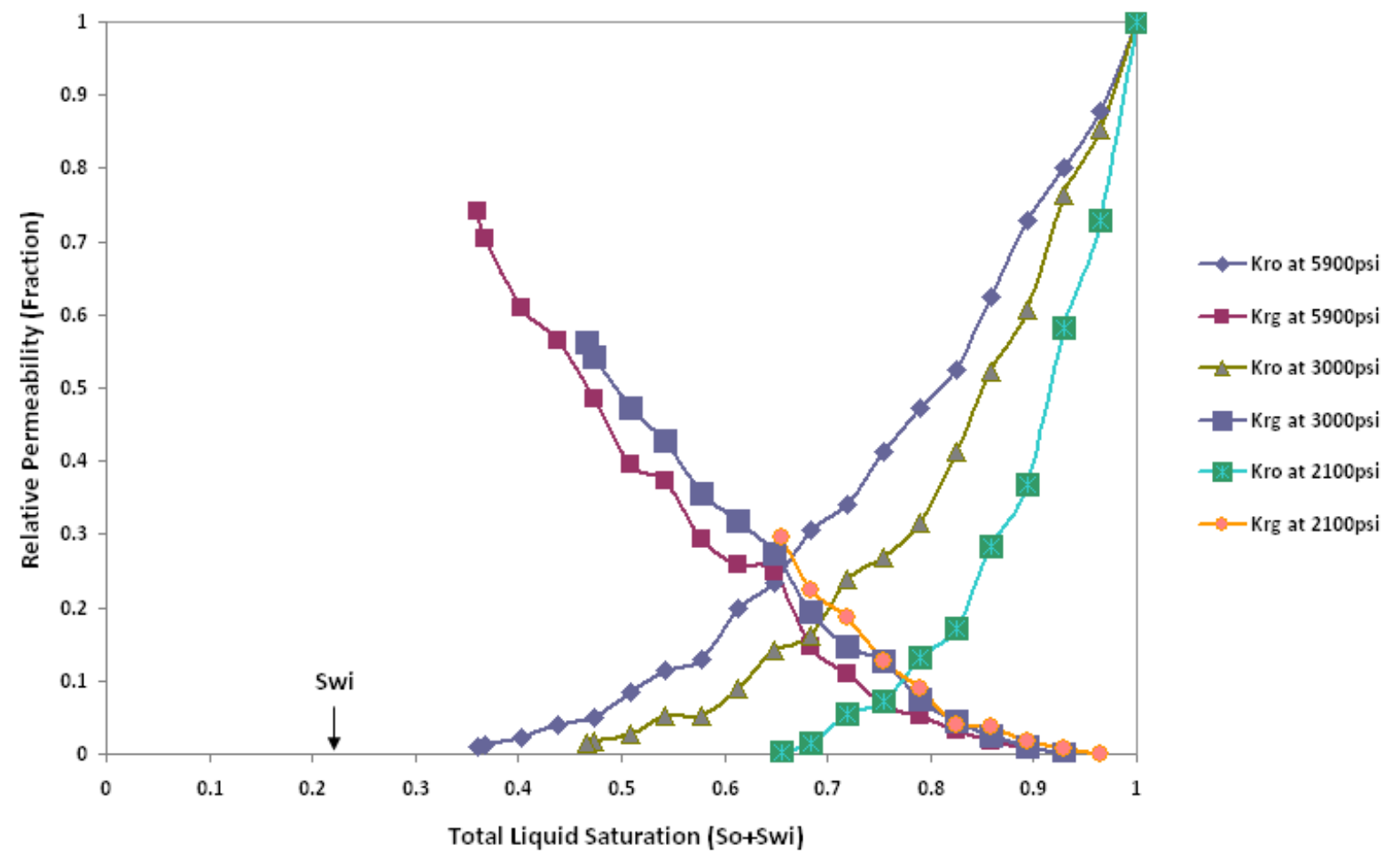

Figure 9: $\mathrm{SCCO}_{2}$ and condensate pressure-dependent relative permeability versus total liquid saturation

At such very low interfacial tension situations, the networks of the two fluids begin to break up at the pore scale level. Ultimately, a mixture bank is formed at the flood front and, at that point, each fluid flows everywhere in proportion to its saturation in the sample, a behaviour that is commonly described by relative permeability curves illustrated in Figure 9 above. This figure explains the condensate recovery efficiency improvement (Figure 7) as miscibility conditions are approached.

\section{Conclusions}

Out of the various factors that affect the micropsic displacement efficiency, this paper has investigated the influence of pressure, phase behaviour and fluid properties associated with $\mathrm{SCCO}_{2}$ injection for IHR. The key to mastering an efficient and profitable extraction of components associated with $\mathrm{CO}_{2}-\mathrm{IHR}$ lie in the phase behaviour and fluid properties of the mixtures. Favourable phase behaviour relationships stimulate the swelling of the condensate volume leading to improved recovery. The density ratio indicate that gravity segregation is expected to be more pronounced at lower injection pressures as the condensate remains the denser phase. Viscosity ratio is another important design parameter that influences the stability of the flood front. Relatively low condensate over $\mathrm{CO}_{2}$ viscosity ratio values at higher pressures results in a stabilising effect on the flood front.

Pressure was found to be a key factor governing the development of miscible displacement conditions in the reservoir. Miscible displacements not only delays gas breakthrough but also improves the sweep efficiency. This paper will serve as a narrow footbridge to the reservoir engineers and technologists to aid the design of their IHR projects. Further research is required to investigate the dependence of recovery profile on different flooding temperatures and on the co-existence of natural gas and condensate in a core sample.

\section{Acknowledgments}

The authors gratefully acknowledge the financial support given to this project from Woodside Energy Ltd, Shell Australia Exploration and Development, and Petroleum Development Oman. 


\section{References}

1. Al-Abri, A., and Amin, R., The impact of $\mathrm{SCCO}_{2}$ injection rate on relative permeability, residual saturation and production performance of natural gas and condensate reservoirs: laboratory investigation. Paper presented at International Energy Agency EOR Conference, Canberra 21-23 September, 2009a.

2. Al-Abri, A., and Amin, R., Experimental investigation of interfacial interactions of condensate/brine/SC- $-\mathrm{CO}_{2}$ systems at high pressures and high temperatures. Paper presented at International Petroleum Technology Conference, Doha 7-9 December, 2009b.

3. Aspen Hysys Simulation Package, AspenTech Co, 2009.

4. Bardon, C., and Langeron, D., Influence of very low interfacial tension on relative permeability. SPE 7609, 1980.

5. Blunt, M., Fayers, F. and Orr, F., Carbon Dioxide in Enhanced Oil Recovery. Energy Convers. Mgmt 34, 1993.

6. Dyer, S., Performance of the immiscible carbon dioxide WAG process at low pressure. MSc Thesis, $U$ of Alberta, Edmonton, Alta, 1989.

7. Green, D. W., and Willhite, G. P., Enhanced Oil Recovery. SPE Textbook Series, Volume 6, 1984.

8. Jakupsstovu, S. I., Zhou, D., Kamath, J., Durlofsky, L., and Stenby, E., H., Upscaling of miscible displacement processes, proceedings of the $6^{\text {th }}$ Nordic Symposium on Petrophysics, Trondheim, Norway, 2001.

9. Monger, T. G., and Coma, J. M., A laboratory and field evaluation of the $\mathrm{CO}_{2}$ huff ' $n$ ' puff process for light oil recovery. SPE Res Eng, 1168-1176, 1988.

10. Monger, T. G., Ramos, J. C., and Thomas, J., Light oil recovery from cyclic $\mathrm{CO}_{2}$ injection: influence of low pressure, impure $\mathrm{CO}_{2}$, and reservoir gas. SPE Res Eng, 25-34, 1991.

11. Moore, T. F., and Slobod, R. L., The effect of viscosity and capillary on displacement of oil by water. Production monthly, pages 20-30, 1956.

12. PVTSim Simulation Package, Release 17, Calsep Co., 2009.

13. Rao, D. N., Gas injection EOR - a new meaning in the new millennium. Journal of Canadian petroleum technology, volume 40, No. 2, pp. 11-18, 2001.

14. Rogers, J. D., and Grigg, R. B., A literature analysis of the WAG injectivity abnormalities in the $\mathrm{CO}_{2}$ process. SPE 59329 presented at the 2000 review SPE/DOE improved oil recovery symposium held in Tulsa, 2000.

15. Rojas, G., Scaled model studies of immiscible carbon dioxide displacement of heavy oil. PhD Thesis, U. of Alberta, Edmonton, Alta, 1985.

16. Rojas, G., and Farouq, S. M., Scaled model studies of carbon dioxide/brine injection strategies for heavy oil recovery from thin reservoirs. Can. Pet. Tech J., 85-94, 1986.

17. Schramm, L. L., Isaacs, E., Singhal, A. K., Hawkins, B., Shulmeister, B., Wassmuth, F., Randall, L., and Turta, A., Technology development for conventional petroleum reservoirs. Journal of Canadian petroleum technology, pp. 31-46, 2000.

18. Shyeh-Yung, J., Mechanism of miscible oil recovery: effect of pressure on miscible and nearmiscible displacement of oil by carbon dioxide. SPE 22651, 1991.

19. Stalkup, F., Miscible Displacement. SPE Monograph, Richardson, Volume 8, 1992.

20. Stegemeier, G. L., Relationship of trapped oil saturation to petrochemical properties of porous media. SPE 4754, 1974.

21. Taber, J. J., Martin, F. D., and Seright, R. S., EOR screening criteria revisited. SPE/DOE 35385 presented at the $10^{\text {th }}$ symposium on improved oil recovery, Tulsa, 1996.

22. Thomas, F. B., Erain, A., Zhou, X., Bennion, D. B., Bennion, D. W., and Okazawa, T., Does miscibility matter in gas injection?. Journal of Canadian petroleum technology presented at the $46^{\text {th }}$ annual technical meeting of the petroleum society in Banff, Alberta, 1995.

23. Thomas, F., B., Holowach, N., Zhou, X., Bennion, D. W., and Bennion, D. W., Miscible or nearmiscible gas injection, which is better. SPE 27811, 1994.

24. Thomas, G., and Monger, T. G., Feasibility of $\mathrm{CO}_{2}$ injection for light oil recovery. SPE Res Eng, 179-184, 1991. 


\section{Appendix 1}

Table 1 - Condensate Composition from Core Laboratory

\begin{tabular}{|c|c|c|c|c|}
\hline Component & Mol\% & Weight $\%$ & \multicolumn{2}{|l|}{ Measured Properties } \\
\hline Methane & 0.00 & 0.00 & Whole Sample Density & 0.8161 g.cc-1 @ 60F \\
\hline Ethane & 0.00 & 0.00 & \multirow{2}{*}{ Whole Sample Mol. Wt. } & 175.8 g.mol-1 \\
\hline Propane & 0.02 & 0.00 & & \\
\hline n-Butane & 0.11 & 0.04 & \multirow{2}{*}{$\begin{array}{l}\text { Plus Fraction } \\
\text { Calculated Properties }\end{array}$} & Density \\
\hline neo-Pentane & 0.00 & 0.00 & & g.cc-1@60 F \\
\hline i-Pentane & 0.23 & 0.10 & \multirow{6}{*}{$\begin{array}{l}\text { Heptanes Plus } \\
\text { Undecanes Plus } \\
\text { Eicosanes Plus } \\
\text { Triacontanes Plus } \\
\text { Hexatriacontanes Plus } \\
\end{array}$} & 0.8179 \\
\hline Hexanes & 1.17 & 0.57 & & 0.8849 \\
\hline M-C-Pentane & 0.54 & 0.26 & & 0.9156 \\
\hline Benzene & 0.47 & 0.21 & & 0.9301 \\
\hline Cyclohexane & 0.80 & 0.38 & & \\
\hline Heptanes & 2.38 & 1.35 & & \\
\hline M-C-Hexane & 2.85 & 1.59 & $\begin{array}{l}\text { Subtotals } \\
\text { Heptanes } \\
\text { Octanes } \\
\text { Nonanes } \\
\text { Decanes } \\
\end{array}$ & Mole \% \\
\hline O-Xylene & 1.24 & 0.75 & & \\
\hline Nonanes & 7.20 & 5.25 & & \\
\hline T-M-Benzene & 0.94 & 0.72 & \multirow{8}{*}{\multicolumn{2}{|c|}{$\begin{array}{l}\text { Notes } \\
\text { Calculated properties derived from Katz \& Firoozabadi } \\
\text { data }\end{array}$}} \\
\hline Decanes & 9.61 & 7.31 & & \\
\hline Undecanes & 8.54 & 7.14 & & \\
\hline Dodecanes & 8.04 & 7.36 & & \\
\hline Tridecanes & 7.88 & 7.85 & & \\
\hline Tetradecanes & 7.11 & 7.68 & & \\
\hline Pentadecanes & 5.37 & 6.29 & & \\
\hline Hexadecanes & 5.80 & 7.33 & & \\
\hline Heptadecanes & 3.21 & 4.32 & \multirow[t]{13}{*}{ This condensate sample } & standard stock tank \\
\hline Hexacosanes & 0.53 & 1.09 & & \\
\hline Heptacosanes & 0.44 & 0.93 & & \\
\hline Octacosanes & 0.38 & 0.83 & & \\
\hline Nonacosanes & 0.31 & 0.72 & & \\
\hline Triacontanes & 0.25 & 0.59 & & \\
\hline Hentriacontanes & 0.22 & 0.53 & & \\
\hline Dotriacontanes & 0.18 & 0.46 & & \\
\hline Tritriacotanes & 0.15 & 0.40 & & \\
\hline Tetratriacontanes & 0.12 & 0.34 & & \\
\hline Pentatriacontanes & 0.10 & 0.29 & & \\
\hline Hexatriacontanes plus & 0.39 & 1.26 & & \\
\hline Totals & 100.00 & 100.00 & & \\
\hline
\end{tabular}

